\title{
Pengaruh Kinerja Aparatur Desa Terhadap Kualitas Pelayanan Kepada Masyarakat di Desa Rantau Mapesai Kecamatan Rengat
}

\author{
Yenny Iskandar ${ }^{1 *}$, Suharmiyati ${ }^{2}$, Reni Maralis $^{3}$ \\ 1,2,3Program Studi Manajemen, Sekolah Tinggi Ilmu Ekonomi Indragiri (STIE-I) Rengat \\ "Correspondence email: yennyiskandar@stieindragiri.ac.id, ${ }^{2}$ suharmiyati@stieindragiri.ac.id, ${ }^{3}$ renimaralis@ stieindragiri.ac.id
}

\begin{abstract}
This research was conducted in Rantau Mapesai village. This research aims to determine the performance influence of village apparatus on the quality of service to the people in Rantau Village Mapesai Sub District Rengat District Indragiri upstream. The population is the total number of people in the region of Rantau Mapesai 993 in 2018 and for the number of samples taken are as many as 91 people. With data analysis used simple linear regression, $F$ test, instrument test, and normality test. The results of the study can be seen that the performance of the village apparatus is very influential in the quality of service to the people in the village of Rantau, it is also supported by the village head assisted staff who are working to guide and control village governance. The presence of village apparatus in society is intended to foster passion, initiative and new ideas in order to improve the lives of its village society.
\end{abstract}

Keywords: Village apparatus performance, quality of service

\section{Pendahuluan}

Perkembangan masyarakat desa yang dinamis dengan semakin tingginya tingkat pendidikan seseorang, pengetahuan dan ketrampilan menuntut profesionalitas yang dimiliki oleh aparat pemerintahan desa untuk meningkatkan kualitas pelayanan bagi masyarakat desa ataupun kelurahan. Aparatur desa merupakan alat dari pemerintah sebagai pelaksana pemerintah terendah. Dalam menjalankan tugas dan fungsinya harus mampu menunjukkan kualitasnya sebagai abdi masyarakat dan abdi Negara. Sebagai abdi masyarakat aparatur pemerintah desa adalah wakil dari masyarakat. Dengan, fungsi gandanya tersebut diharapkan aparatur pemerintah desa mampu mewakili masyarakat yang dipimpinnya. Pemerintah Desa di bawah pimpinan Kepala Desa memiliki tugas yaitu: 1) menyelenggarakan urusan pemerintahan, pembangunan dan kemasyarakatan secara efisien dan akuntabel, 2) melaksanakan urusan pemerintahan yang dilimpahkan oleh Bupati. Dengan demikian Pemerintah Desa dapat menjalankan fungsi administrasi pemerintahan, pemberdayaan masyarakat, pelayanan masyarakat, penyelenggaraan ketentraman dan ketertiban umum, pemeliharaan prasarana dan fasilitas umum, dan pembinaan lembaga masyarakat. Namun demikian yang terjadi di tingkat pemerintahan terendah yaitu desa atau kelurahan justru banyak terjadi kejadiankejadian yang menyangkut rendahnya pelayanan pemerintahan kepada masyarakat baik secara kualitas maupun kuantitas. Masyarakat secara umum masih sering mengeluhkan para aparatur pemerintah desa yang kurang pengertian pada kebutuhan warga. Untuk memperoleh pelayanan yang sederhana saja masyarakat sering dihadapkan pada kesulitan, misalnya prosedur yang berbelit-belit. Aparat pemerintah desa kurang merasa terpanggil untuk meningkatkan efisiensi dan memperbaiki prosedur kerja. Ada kecenderungan aparat pemerintah desa mempertahankan status quo, sehingga menimbulkan persepsi masyarakat bahwa berhubungan dengan pemerinta desa (birokrasi) berarti berhadapan dengan proses yang berbelit-belit disamping itu prosedur yang sulit ditumpangi oleh kepentingan pribadi dan dijadikan komoditas yang diperdagangkan untuk kepentingan pribadi atau kelompok.

Tabel 1

Data Mengenai Pelayanan yang Telah dilakukan Aparatur Desa pada Kantor Desa Rantau Mapesai Kecamatan Rengat Kabupaten Indragiri Hulu Tahun 2019

\begin{tabular}{ll}
\hline \multicolumn{1}{c}{ Surat } & \multicolumn{1}{c}{ Waktu Penyelesaian } \\
\hline KK & 1 ( satu ) Hari \\
KTP & 1 (satu) atau 2(dua) Hari \\
Akte Kelahiran & 1 ( satu ) Hari \\
Surat Keterangan Ganti Rugi & 1 ( satu ) Minggu \\
\hline
\end{tabular}

Sumber: Kantor Desa Rantau Mapesai Kec. Rengat Kabupaten Indragiri Hulu, Tahun 2020

Gaya manajemen yang telah berorientasi kepada tugas (Task Oriented) juga membawa pengaruh tidak terpacunya pegawai kepada hasil dan kualitas pelayanan umum. Dan dibawah ini tabel penjelasan mengenai jumlah aparatur desa Rantau Mapesai. 
Yenny Iskandar et al, Pengaruh Kinerja Aparatur Desa Terhadap Kualitas Pelayanan Kepada Masyarakat di Desa Rantau Mapesai Kecamatan Rengat

Tabel 2

Data Jumlah Aparatur Desa dan Masyarakat pada Kantor Desa Rantau Mapesai Kecamatan Rengat Kabupaten Indragiri Hulu Tahun 2017-2019

\begin{tabular}{lrrr}
\hline \multicolumn{1}{c}{ Keterangan } & $\mathbf{2 0 1 7}$ & $\mathbf{2 0 1 8}$ & $\mathbf{2 0 1 9}$ \\
\hline Kepala Desa & 1 Orang & 1 Orang & 1 Orang \\
Sekretaris Desa & 1 Orang & 1 Orang & 1 Orang \\
Kaur \& Kasi Kantor Desa & 4 Orang & 4 Orang & 4 Orang \\
Kepala Dusun & 2 Orang & 2 Orang & 2 Orang \\
RW/RT & 7 Orang & 7 Orang & 7 Orang \\
Staff Kantor Desa & 4 Orang & 4 Orang & 4 Orang \\
Masyarakat & 839 Orang & 896 Orang & 974 Orang \\
Jumlah & 858 Orang & 915 Orang & 993 Orang \\
\hline
\end{tabular}

Sumber: Kantor Desa Rantau Mapesai Kec. Rengat Kabupaten Indragiri Hulu, Tahun 2020

Idealnya, aparatur Pemerintah Desa memberikan pelayanan pada masyarakat Misalnya dalam urusan pemenuhan kebutuhan pokok dan layanan yang bersifat administsratif kependudukan seperti Kartu Keluarga (KK), KTP, kelahiran, pernikahan, kematian. Kurangnya pengetahuan warga masyarakat tentang peran dan fungsi Pemerintah Desa, ketidaktahuan tentang program Pemerintah Desa, dan ketidaktahuan tentang kebutuhan mereka berkaitan dengan Pemerintah telah menjadikan warga masyarakat tidak memiliki cukup kontrol terhadap tugas-tugas yang dijalankan oleh Pemerintah Desa. Kebutuhan masyarakat terhadap dokumen kependudukan di atas membuat Pemerintah Desa harus melaksanakan tugas-tugas kepemerintahan lebih berat daripada sebelumnya. Apalagi, di internal masyarakat terjadi perbedaan persepsi dan kepentingan mengenai bantuan berupa dana rekonstruksi (dakon) hingga memunculkan konflik horisontal di masyarakat. Untuk lebih jelasnya kita table mengenai kehadiran aparatur desa di Desa Rantau Mapesai Kecamatan. Rengat.

Tabel 3

Absensi Aparatur Desa pada Kantor Desa Rantau Mapesai Kec. Rengat Kabupaten Indragiri Hulu tahun 2017-2019

\begin{tabular}{|c|c|c|c|c|c|c|}
\hline Tahun & Jumlah Pegawai & Jumlah Hari Kerja & Sakit & Izin & $\begin{array}{l}\text { sensi } \\
\text { Tanpa Keterangan }\end{array}$ & Persentase kehadiran \\
\hline 2017 & 19 & 264 & 10 & 6 & 5 & 92,04 \\
\hline 2018 & 19 & 264 & 10 & 5 & 5 & 92,42 \\
\hline 2019 & 18 & 264 & 12 & 7 & 10 & 89,01 \\
\hline
\end{tabular}

Sumber : Kantor Desa Rantau Mapesai Kec. Rengat Kabupaten Indragiri Hulu, Tahun 2020

Upaya untuk mengendalikan konflik berkaitan dengan pembagian dakon ini telah dilakukan dengan upaya-upaya hukum maupun rekonsiliasi antar warga. Berbagai persoalan di atas sedikit banyak telah mempengaruhi masyarakat untuk menuntut pemerintah agar menciptakan pemerintahan yang baik (good government) agar aparatur pemerintah desa dapat menjalankan tugas pelayanan kepada masyarakat dengan lebih baik. Tujuan penelitian ini adalah untuk mengkaji pengaruh Kinerja aparatur desa terhadap kualitas pelayanan kantor desa Rantau Mapesai Kecamatan Rengat Kabupaten Indragiri Hulu.

\section{Tinjauan Pustaka \\ Kinerja}

Kinerja adalah fungsi dari kemampuan (ability), motivasi (motivation) dan peluang (opportunity). mengemukakan bahwa motivasi kerja merupakan kondisi yang membangkitkan, mengarahkan dan memelihara perilaku yang berhubungan dengan lingkungan kerja. Hubungan ketiganya dapat dijelaskan sebagai berikut. Suatu kemampuan, baik kemampuan mental, fisik, pengetahuan maupun keterampilan tidak akan berarti tanpa adanya dorongan atau motivasi individu untuk menjalankannya. Meskipun sudah ada kemampuan dan motivasi, jika tidak ada kesempatan maka tidak akan terjadi suatu unjuk kerja yang dapat menunjukkan kinerja seseorang.(Mangkunegara, 2007). Kinerja merupakan prestasi kerja, yakni perbandingan antara hasil kerja yang dapat dilihat secara nyata dengan standar kerja yang telah ditetapkan organisasi. Kinerja menurut (Iskandar 2019) adalah hasil karya seseorang dalam bentuk kualitas ataupun kuantitas dalam suatu organisasi.

Kinerja adalah kemampuan kerja atau suatu prestasi yang dicapai serta yang perlukan. Dengan demikian kinerja dapat dilihat dari beberapa dimensi yang berbeda, yang pertama adalah kinerja sebagai hasil atau output yaitu menilai kinerja melihat apa yang telah dicapai oleh seseorang. Kedua adalah kinerja dilihat dari aspek prosesnya. Bagaimana prosedur-prosedur yang telah dilaluinya dan ditempuh seseorang dalam menyelesaikan tugasnya. Dan dimensi lain adalah ditinjau dari aspek kontekstualnya yakni kemampuan sendiri (personal ability) yang dimiliki oleh seorang karyawan.(Preffer, 2007). Manajemen kinerja adalah manajemen tentang menciptakan hubungan dan memastikan 
komunikasi yang efektif. Manajemen kinerja memfokuskan pada apa yang diperlukan oleh organisasi, manajer, dan pekerja untuk berhasil (Wibowo, 2014)

Kinerja pemerintah mencakup dalam hal pelayanan, pemberdayaan dan pembangunan. Pelayanan yang dimaksud adalah pelayanan kepada publik sesuai dengan wewenang yang dimiliki oleh masing-masing instansi. Dalam hal ini, pelayanan oleh instansi Pemerintah Desa adalah pelayanan kepada masyarakat di desanya. (Rasyid, 1997). Kinerja pemerintah dalam pelayanan kepada masyarakat sangat dipengaruhi oleh keahlian dan kecakapan aparatnya, terutama mengenai kecakapan kerja yang dimilikinya selama mereka menempati posisi sebagai lembaga pelayanan. Hal tersebut tidak terlepas dari kinerja yang ada di dalam lingkungan lembaga pemerintah yang bersangkutan. Kinerja sendiri pada dasarnya adalah gambaran mengenai tingkatan, pencapaian pelaksanaan suatu kegiatan atau program atau kebijaksanaan dalam mewujudkan sasaran, tujuan, misi, dan visi organisasi. Beberapa konsep indikator lagi tentang penilaian terhadap Kinerja Aparatur Pemerintah Daerah sebagai berikut: konsistensi pencapaian tujuan, produktifitas, kualitas pelayanan, responsivitas, responbilitas, akuntabilitas dan kualitas perlindungan masyarakat (Yudoyono, 2001)

\section{Kualitas Pelayanan}

Pelayanan ialah menolong untuk menyediakan segala sesuatu yang diperlukan oleh orang lain diantaranya adalah pembeli, konsumen, nasabah dan masyarakat. Pelayanan dapat diberikan kepada orang lain sebagai pertolongan yang dibutuhkan orang lain itu sendiri. Yang mana dengan pertolongan tersebut dapat membantu orang lain untuk bisa mengatasi masalahnya. Kualitas pelayanan menurut (Hermanto et al. 2019) adalah suatu layanan yang diberikan organisasi itu harus menjamin efisiensi dan keadilan serta harus memiliki kualitas yang mantap. Kualitas merupakan harapan semua orang atau pelanggan. Pelayanan (Service) ialah sebagai suatu tindakan ataupun kinerja yang bisa diberikan pada orang lain. Pelayanan atau juga lebih dikenal dengan service bisa di klasifikasikan menjadi dua yaitu. (Kotler, 2003)

a. High contact service ialah sebuah klasifikasi dari sebuah pelayanan jasa dimana kontak diantara konsumen dan juga penyedia jasa yang sangatlah tinggi, konsumen selalu terlibat di dalam sebuah proses dari layanan jasa tersebut.

b. Low contact service ialah klasifikasi pelayanan jasa dimana kontak diantara konsumen dengan sebuah penyedia jasa tidaklah terlalu tinggi. Physical contact dengan konsumen hanyalah terjadi di front desk yang termasuk ke dalam klasifikasi low contact service. Misalkan lembaga keuangan.

Dalam konteks pelayanan kepada publik, menurut Rasyid di atas, birokrasi dibentuk untuk mengabdi atau melayani kebutuhan public. Konsep kepentingan public didefinisikan melalui pemehaman berikut ini:

\section{Metode}

Penelitian ini dilaksanakan dengan menggunakan pendekatan diskriptif kualitatif dengan pertimbangan bahwa peneliti bermaksud untuk mendapatkan gambaran tentang pengaruh kinerja aparatur desa terhadap kualitas pelayanan yang diberikan kepada masyarakat dan upaya untuk meningkatkan kinerja aparatur pemerintah Desa Rantau Mapesai Kecamatan Rengat Kabupaten Indragiri Hulu.Teknik Pengumpulan data dalam Penelitian ini, menggunakan teknik pengumpulan data melalui tahapan mulai dari kuisioner, wawancara dan Dokumentasi. Model dalam penelitian ini adalah teknik analisis dengan menggunakan model wawancara yang meliputi tiga komponen analisis yaitu reduksi, sajian data, penarikan kesimpulan. Miles dan Huberman (dalam Sugiaono 2013). Penelitian ini dilakukan pada salah satu desa di Kecamatan Rengat Kabupaten Indragiri Hulu dengan pendekatan kuantitatif. Penelitian ini termasuk jenis penelitian deskriptif, menurut Arikunto (2010), menjelaskan bahwa penelitian deskriptif adalah suatu bentuk penelitian yang paling besar ditunjukkan untuk menggambarkan kejadian-kejadian yang ada. Ciri-ciri metode deskriptif adalah: 1) Memusatkan diri pada permasalahan yang ada pada masa sekarang dan masa aktual dan 2) Data yang dikumpulkan mula-mula disusun, dijelaskan kemudian dianalisa. Penelitian ini dilakukan di Kabupaten Indragiri Hulu. Jenis data yang digunakan dalam penelitian ini adalah data primer dan sekunder,.

Populasi dalam penelitian ini adalah masyarakat yang berada di Desa Rantau Mapesai yaitu berjumlah 993 orang, pada tahun terakhir penelitian. Jadi untuk mempermudah dalam memperoleh persentase jawaban tersebut, penelitian hanya mengambil sampel Accidental random sampling yaitu mengambil responden secara acak sebagai sampel berdasarkan kebetulan, yaitu siapa saja yang secara kebetulan bertemu dengan peneliti dapat digunakan sebagai sampel bila orang yang kebetulan ditemui cocok sebagai sumber data. Teknik ini biasanya dilakukan karena keterbatasan waktu, tenaga, dan dana sehingga tidak dapat mengambil sampel yang besar dan jauh. dengan menggunakan rumus slovin yang dangkat sebagai bahan sample pada penelitian ini. (Sugiyono 2010). Jumlah sampel penelitian ini adalah sebanyak 91 responden.

Variabel dalam penelitian ini adalah kinerja dan kualitas Pelayanan dan berupa angket yang akan diisi langsung oleh masyarakat desa Rantau Mapesai Kecamatan Rengat Kabupaten Indragiri Hulu. 


\section{Instrumen Penelitian}

Instrumen yang dipergunakan dalam penelitian ini adalah angket atau kuesioner yang disusun menggunakan skala liker dengan beberapa pilihan yaitu: Sangat Setuju (SS), Setuju (S), Cukup Setuju (CS), Tidak Setuju (TS), dan Sangat Tidak Setuju (STS). Dalam penelitian ini dilakukan analisis distribusi frekuensi dan mean (nilai rata-rata) untuk memberikan gambaran mengenai kecenderungan tanggapan responden. Teknik analisis data yang digunakan regresi linear sederhana dengan persamaan: $\mathrm{Y}=\mathrm{a}+\mathrm{bX}+\mathrm{e}$

Keterangan : $\mathrm{Y}=$ Kinerja; $\mathrm{X}=$ Kualitas Pelayanan; $\mathrm{a}=$ Besarnya nilai $\mathrm{Y}$ apabila $\mathrm{X}=$ nol; $\mathrm{b}=$ Besarnya peningkatan $\mathrm{Y}$ apabila $\mathrm{X}$ meningkat 1 satuan

\section{Uji $t$}

Uji yang dilakukan untuk koefisien regresi ini adalah uji statistik:

Apabila $\mathrm{t}$ hitung $>\mathrm{t}$ tabel artinya Ha diterima dan Ho ditolak, maka ada korelasi yang signifikan antara variabel $\mathrm{X}$ dan Variabel Y

Apabila t hitung $<\mathrm{t}$ tabel artinya Ha ditolak dan Ho diterima, maka tidak ada korelasi yang signifikan antara variabel $\mathrm{X}$ dan Variabel Y.

\section{Hasil}

Tanggapan responden mengenai kinerja Aparatur Desa pada Kantor Desa Rantau Mapesai Kecamatan Rengat Kabupaten Indragiri Hulu. Dalam variabel kinerja Aparatur Desa terdapat enam item pernyataan sebagai berikut dan rata-rata tingkat Kinerja Aparatur Desa sebesar 4,20 yang tergolong dalam opsi setuju artinya hasil kerja baik secara kualitas maupun kuantitas yang dicapai oleh Aparatur Desa dalam melakukan tugas sesuai dengan tanggung jawab yang diberikan kepadanya.

\section{Analisis Kualitas Pelayanan}

Tanggapan responden mengenai Kualitas Pelayanan pada Kantor Desa Rantau Mapesai Kecamatan Rengat Kabupaten Indragiri Hulu. Dalam variabel Kualitas pelayanan terdapat lima item pernyataan sebagai berikut dan ratarata kualitas pelayanan sebesar 4,11 yang termasuk kriteria setuju, artinya kualitas pelayanan yang telah di berikan oleh aparatur desa pada Kantor Desa Rantau Mapesai Kecamatan Rengat Kabupaten Indragiri Hulu tergolong baik, hal ini disebabkan adanya pimpinan yang peduli dengan aparatur desa dan pemberian kompensasi serta pendukung lainnya di dalam kantor desa tersebut .

\section{Analisis Pengaruh Kinerja terhadap Kualitas Pelayanan}

Tabel 4

Koefisien

\begin{tabular}{llrrrrr}
\hline & \multirow{2}{*}{ Model } & \multicolumn{2}{c}{ Unstandardized Coefficients } & Standardized Coefficients & t & Sig. \\
& & B & Std. Error & Beta & 3.178 \\
\hline 1 & (Constant) & 6.954 & 2.188 & .002 \\
& Kinerja Aparatur Desa & .513 & .082 & .000 \\
\hline
\end{tabular}

Sumber: data olahan

Berdasarkan data SPSS Versi 24 diketahui bahwa konstanta ( $\alpha$ ) adalah 6,954 dan koefisien $X\left(\beta_{1}\right)$ adalah 0,513 dengan persamaan regresi sederhana adalah $\mathrm{Y}=6,954+0,513 \mathrm{X}$

Tabel 5

Model Summary

\begin{tabular}{clrrrr}
\hline Model & R & R Square & Adjusted R Square & Std. Error of the Estimate & Durbin-Watson \\
\hline 1 & $.551^{\mathrm{a}}$ & .304 & .296 & .298 \\
\hline
\end{tabular}

Sumber: data olahan

Pada tabel di atas diketahui bahwa (X) Kinerja mempunyai hubungan dengan (Y) Kualitas Pelayanan. Hal ini dapat dilihat dari nilai koefisien korelasi berganda $\mathrm{R}$ adalah 0,551 artinya memiliki hubungan yang sedang. dan selanjutnya diuji dengan Koefisien determinasi berganda $\left(\mathrm{R}^{2}\right)$ adalah 0,304 . hal ini menunjukkan bahwa (X) Kinerja dapat memberikan sumbangan terhadap variabel (Y) Kualitas Aparatur Desa sebesar 30,4 \%. Dan sisanya 69,6 \% di pengaruhi oleh variabel lain yang tidak diteliti dalam penelitian ini. 
Yenny Iskandar et al, Pengaruh Kinerja Aparatur Desa Terhadap Kualitas Pelayanan Kepada Masyarakat di Desa Rantau Mapesai Kecamatan Rengat

Tabel 6

Model Anova

\begin{tabular}{|c|c|c|c|c|c|c|}
\hline & Model & Sum of Squares & $\mathrm{df}$ & Mean Square & $\mathrm{F}$ & Sig. \\
\hline \multirow[t]{3}{*}{1} & Regression & 54.786 & 1 & 54.786 & 38.853 & $.000^{\mathrm{b}}$ \\
\hline & Residual & 125.499 & 89 & 1.410 & & \\
\hline & Total & 180.286 & 90 & & & \\
\hline
\end{tabular}

Sumber: data olahan

Tabel diatas dapat dilihat F hitung yaitu 38,853 sedangkan F tabel dapat diperoleh dengan menggunakan tabel F dengan derajat bebas (df) residual (sisa) yaitu 91 sebagai df penyebut dan df Regresion (perlakuan) yaitu 2 sebagai df pembilang dengan taraf signifikan 0,05, sehingga diperoleh F tabel 3,25. karena F hitung $(38,853)>\mathrm{F}$ tabel $(2,061)$ maka Ho ditolak dan Ha diterima. Artinya variabel Kinerja memiliki pengaruh signifikan terhadap Kualitas Pelayanan aparatur desa pada Kantor Desa Rantau Mapesai Kecamatan Rengat Kabupaten Indragiri Hulu.

\section{Simpulan}

Hasil penelitian ini adalah sebagai berikut:

1. Variabel Kinerja aparatur desa memiliki pengaruh terhadap kualitas pelayanan kepada masyarakat dalam meningkatkan pelayanan birokrasi pemerintah desa berdasarkan kuisioner yang disebarkan dan hal ini sudah sesuai dengan harapan masyarakat, disini di lihat bahwa aparatur desa sudah mengoptimalkan kepemimpinan dan kompetensi kedalam pelaksanaan pekerjaannya.

2. Upaya yang telah dilakukan aparatur desa dalam meningkatkan perilaku tanggung jawab aparatur desa terhadap tugas- tugasnya sudah berjalan dengan baik seperti pelayanan surat- menyurat kepada masyarakat yang berjalan lancar. Hal ini di dorong dengan adanya kuantitas, kualitas, motivasi dan penghargaan berupa uang atau barang seperti kepala desa memberikan pakaian terhadap aparatur desa. Mengingat motivasi dari atasan merupakan unsur penting dalam pekerjaan yang berimbas pada tanggung jawabnya sebagai seorang aparatur desa di dalam mengerjakan tugas- tugasnya.

\section{Daftar Pustaka}

As’ad, M., 1998. Psikologi Industri, Seri Ilmu Sumber Daya Manusia, Edisi Keempat, Liberty, Yogyakarta.

Hermanto, Roky Apriansyah, Khusnul Fikri, and Albetris. 2019. "Pengaruh Lokasi Dan Kualitas Pelayanan Terhadap Loyalitas Konsumen Pada Fotocopy Anugrah Rengat.” Ekonomis: Journal of Economics and Business 3(2): 171-76.

Indonesia Corruption Watch (ICW), 2000. Hasil Survei Korupsi di Pelayanan Publik, Studi Kasus di Lima Kota. Jakarta. Iskandar, Yenny. 2019. "Pengaruh Motivasi Dan Pemberian Kompensasi Terhadap Kinerja Agen Asuransi pada PT . Prudential Life Assurance Kecamatan Rengat Barat." VIII(01): 61-69.

Kotler Amstrong, 2008. prinsip- prinsip pemasaran 2. Edisi ke Duabelas, Erlangga. Jakarta

Loina Perangin- angin, 2001. Hubungan Masyarakat: Membina Hubungan Baik dengan public, CV. Lalolo, Bandung.

Mangkunegara, Anwar Prabu, A.A., 2007. Manajemen Sumber Daya Manusia, Rosda Karya, Bandung.

Preffer, Jeffrey, 2007,Paradigma Baru Manajemen Sumber Daya Manusia, Amara Books, Yogyakarta.

Rasyid Ryaas, 1997. Pembangunan Pemerintahan Indonesia Memasuki Abad 21, Pidato Pengukuhan Guru Besar Tetap Ilmu Politik pada Institut Ilmu Pemerintahan, Jakarta.

Undang-Undang No.32 Th 2004 tentang Pemerintahan Daerah.

Wibowo, 2014, Manajemen Kinerja Edisi Kelima, PT Rajagrafindo persada, Jakarta.

Yudoyono Bambang, 2001. Desentralisasi dan Pengembangan SDM Aparatur Pemda dan Anggota DPRD. Pustaka Sinar Harapan, Jakarta. 